\title{
Liver and muscle insulin sensitivity, glycogen concentration and glycogen synthase activity in a rat model of non-insulin-dependent diabetes
}

\author{
Y.T. Kruszynska ${ }^{1}$ and P.D. Home ${ }^{2}$ \\ Departments of Medicine, ${ }^{1}$ Royal Free Hospital, London and ${ }^{2}$ University of Newcastle upon Tyne, UK
}

Summary. Mild diabetes was induced in adult rats with streptozotocin ( $45 \mathrm{mg} / \mathrm{kg}$ body weight), and insulin sensitivity, glycogen deposition and glycogen synthase activity assessed in liver and muscle 5 weeks later. Diabetic rats had significantly elevated fasting blood glucose concentrations (5.6士 0.1 versus $3.6 \pm 0.1 \mathrm{mmol} / 1, p<0.001$ ), and blood glucose concentrations $2 \mathrm{~h}$ after a $1 \mathrm{~g} / \mathrm{kg}$ glucose load $(12.0 \pm$ 0.6 versus $3.7 \pm 0.2 \mathrm{mmol} / 1, p<0.001$ ). After a 20 -h fast hepatic glucose output was significantly elevated $(58 \pm 3$ versus $47 \pm 3 \mu \mathrm{mol} \cdot \mathrm{min}^{-1} \cdot \mathrm{kg}^{-1}, p<0.05$ ), and failed to suppress at high insulin concentrations during a euglycaemic clamp (hepatic glucose output $21 \pm 4$ versus $2 \pm 4 \mu \mathrm{mol} \cdot \mathrm{min}^{-1} \cdot \mathrm{kg}^{-1}$, $p<0.02$ ). Liver glycogen was lower in the diabetic rats by the end of the clamp $(16 \pm 3$ versus $38 \pm 6 \mu \mathrm{mol} / \mathrm{g}$ wet wt, $p<$
0.05). At the end of the clamp total glucose turnover was lower in the diabetic rats $\left(107 \pm 4\right.$ versus $161 \pm 17 \mu \mathrm{mol} \cdot \mathrm{min}^{-1}$. $\mathrm{kg}^{-1}, p<0.01$ ), as was skeletal muscle glycogen synthase activity $(0.46 \pm 0.04$ versus $0.67 \pm 0.05 \mathrm{U} / \mathrm{g}$ wet $\mathrm{wt}, p<0.01)$ and glycogen concentration ( $22 \pm 2$ versus $33 \pm 3 \mu \mathrm{mol} / \mathrm{g}$ wet wt, $p<0.05$ ). Blood lactate and pyruvate responses suggested that glycolytic pathways were similarly affected. Thus, insulin insensitivity develops in both liver and skeletal muscle after 5 weeks of mild streptozotocin-induced diabetes.

Key words: Insulin sensitivity, glycogen, glycogen synthase, non-insulin-dependent diabetes, rat, glucose turnover, intermediary metabolites.
It is well documented that in Type 2 (non-insulin-dependent) and Type 1 (insulin-dependent) diabetes abnormalities of both insulin secretion and insulin sensitivity may be demonstrated in the overwhelming majority of individual patients [1-8]. In Type 1 diabetes there is little argument that the primary lesion is destruction of the B cell of the islets of Langerhans, while the insulin insensitivity is believed to be secondary. However, whether this results from periods of hypoinsulinaemia or hyperinsulinaemia, hyperglycaemia, excessive counter-regulatory hormone secretion, or unidentified factors is unclear. In Type 2 diabetes it is not understood whether the similar pattern of metabolic abnormalities also results from a primary insulin secretory abnormality, or whether it is secondary to the demonstrable abnormalities of insulin action. Thus both abnormalities are demonstrable even in people with mildly abnormal glucose tolerance [9], or women who previously had gestational diabetes [10]. Reaven has suggested that insulin insensitivity is the more basic lesion [11], while in studies of relatives of people with diabetes Turner and others have suggested that islet Bcell dysfunction is more marked at an early stage [12].

Although insulin treatment can reverse some of the metabolic abnormalities of Type 2 it has not proved possible to normalise them [5-7]. An alternative approach is to ask whether it is possible to reproduce the metabolic picture of Type 2 diabetes through a disturbance of B-cell function alone [13, 14]. Unfortunately, most forms of pancreatic damage in man are associated with agents that may cause hepatic damage, though partial pancreatectomy has been used to model non-insulin-dependent diabetes in rats [15]. Streptozotocin in large doses has been shown in islet transplantation studies not to cause long term tissue damage to non-islet tissue [16, 17], however, and we have therefore used much smaller doses to induce mild diabetes in adult rats. This is an alternative approach to the neo-natal streptozotocin model of Bonner-Weir and others [18]. We have then assessed whether abnormalities of glucose production, glucose storage, or glycogen synthase activity are detectable in liver and skeletal muscle. 


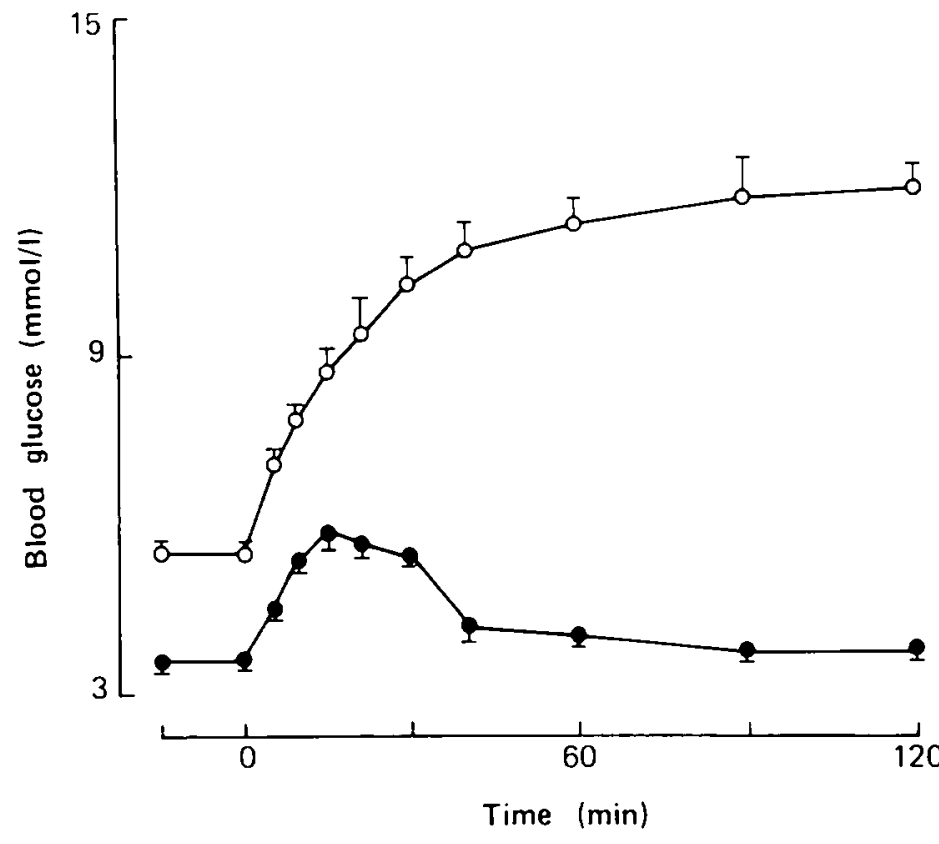

Fig. 1. Blood glucose concentrations, in normal rats $(0)$, and in diabetic rats $(\mathrm{O}) 4$ weeks after receiving streptozotocin $45 \mathrm{mg} / \mathrm{kg}$, in response to oral glucose $1 \mathrm{~g} / \mathrm{kg}$ body weight.

\section{Material and methods}

\section{Animals}

Diabetes was induced in male Wistar rats $(180190 \mathrm{~g})$ by intravenous injection of streptozotocin ( $45 \mathrm{mg} / \mathrm{kg}$ body weight). Rats were maintained on standard laboratory chow. Five rats $(12 \%)$ failed to gain weight after injection. Weight gain in the remaining $88 \%$ of streptozotocin-injected rats was similar to that of the control rats, so that at the time of study this group of diabetic rats weighed $320 \pm 7 \mathrm{~g}$ (SD) compared to $318 \pm 6 \mathrm{~g}$ in control rats. Four weeks after streptozotocin injection, rats with $24 \mathrm{~h}$ fasted blood glucose concentrations equal to or greater than $5.0 \mathrm{mmol} / \mathrm{l}$ were selected as being possibly diabetic. Approximately $35 \%$ of streptozotocin-injected rats satisfied the selection criteria. This was confirmed by an oral glucose tolerance test ( $1 \mathrm{~g} / \mathrm{kg}$ body weight) performed on 24 -h fasted, conscious, unrestrained rats with jugular venous cannulae implanted $24 \mathrm{~h}$ before study (Fig. 1). A group of normal littermate control rats were also studied.

\section{Radioisotopic glucose turnover and euglycaemic clamp studies}

Basal glucose turnover studies were performed on 14 diabetic and 14 normal control rats 5 weeks after injection of streptozotocin and at least 7 days after the oral glucose tolerance test. Insulin sensitivity was then assessed by the euglycaemic clamp technique [19] in 7 of the diabetic and 7 of the normal control rats. Jugular and femoral venous cannulae were inserted under ether anaesthesia $24 \mathrm{~h}$ before study. Euglycaemic clamps were performed on conscious, unrestrained animals fasted for $20 \mathrm{~h}$.

After basal blood samples for glucose, insulin and intermediary metabolite concentrations, a primed continuous infusion of $3-3 \mathrm{H}$ glucose $(0.04 \mu \mathrm{Ci} / \mathrm{min})$ and $\mathrm{U}-14 \mathrm{C}$ glucose $(0.03 \mu \mathrm{Ci} / \mathrm{min})$ diluted in Haemaccel (Hoechst, Frankfurt am Main, FRG) was begun, and continued for $60 \mathrm{~min}$. Blood samples $(100 \mu \mathrm{l})$ were taken from the femoral venous cannula at $30,50,55$ and $60 \mathrm{~min}$ for determination of plasma glucose concentration and plasma glucose specific activity. At this stage 7 rats in each group were killed for tissue metabolic studies. From 60 min highly purified human insulin (Actrapid, Novo
Industri, Bagsvaerd, DK) diluted in Haemaccel $(85 \mathrm{~mL} / \mathrm{h})$ was infused for $2.5 \mathrm{~h}$ through one limb of a double lumen cannula (Miles, Stoke Poges, UK) connected to the jugular venous cannula. This solution also contained glucose tracer to give an increased infusion rate of $0.12 \mu \mathrm{Ci} / \mathrm{min}$ of $3-3 \mathrm{H}$-glucose and $0.09 \mu \mathrm{Ci} / \mathrm{min}$ of $\mathrm{U}-14 \mathrm{C}$ glucose, throughout the clamp, thus maintaining glucose specific activity at higher turnover rates. Blood samples for glucose $(30 \mu \mathrm{l})$ were taken at 5-10 min intervals from the femoral venous cannula and replaced with $0.15 \mathrm{~mol} / \mathrm{l}$ saline. Blood samples were taken for insulin estimation at 150,180 and $210 \mathrm{~min}(100 \mathrm{\mu l})$ for intermediary metabolites $(150 \mu \mathrm{l})$ at $180 \mathrm{~min}$, and for glucose specific activity $(80 \mu \mathrm{l})$ at 10-min intervals between 180 and $210 \mathrm{~min}$, and were replaced with an equal volume of fresh washed rat erythrocytes in $0.15 \mathrm{~mol} / 1 \mathrm{sa}-$ line. Blood glucose concentrations were maintained at $4.0 \mathrm{mmol} / \mathrm{l}$ by a variable infusion of $500 \mathrm{~g} / 1$ glucose in water through the other arm of the double lumen cannula.

At the end of the basal turnover studies, and at +210 min while maintaining the clamp, 7 rats in each group were anaesthetised by intravenous injection of $9 \mathrm{mg}$ pentobarbitone (May \& Baker, Manchester, UK, $60 \mathrm{~g} / \mathrm{l}$ ) and liver and quadriceps skeletal muscle freezeclamped, ground under liquid nitrogen and stored at $-70^{\circ} \mathrm{C}$ until assayed for glycogen content and glycogen synthase activity.

For determination of glucose specific activity, plasma was immediately deproteinised with barium hydroxide: zinc sulphate [20] and the neutral extract passed down a column of AG2-X8 anion exchange resin (Bio-Rad, Richmond, Calif, USA). The column was eluted with deionised water, and the eluate freeze-dried. Radioactivity was determined in a liquid scintillation counter (Beckman, High Wycombe, UK) using an external standard to correct for efficiency and overlapping. Minimum recovery after deprotcinisation, neutralisation, passage through the column, and freeze drying was $91 \%$. Triplicate aliquots of the basal and clamp infusion fluids were processed in a manner identical to the plasma samples. Steady state glucose specific activity was reached by 30 min during the basal turnovers and also by $180 \mathrm{~min}$ during the clamps. The mean of the last 3 plasma glucose specific activity determinations in each period was therefore used in the calculation of glucose turnover. As glucose disintegrations per minute (DPM) were estimated in plasma, plasma rather than blood glucose concentration was measured during turnover studies. Due to the very low content of erythrocyte glucose transporters, blood glucose in rats is significantly lower than plasma glucose $(50 \%$ at $6.0 \mathrm{mmol} / \mathrm{l})$. Glucose turnover was estimated from the formula:

Glucose turnover $=\frac{\text { tracer infused }(\mathrm{DPM})}{\text { glucose specific activity }(\mathrm{IPM} / \mu \mathrm{mol})}$

Glucose carbon recycling was calculated as [21]:

$\frac{3 \mathrm{H} \text {-glucose turnover }-14 \mathrm{C} \text { glucose turnover }}{3 \mathrm{H} \text {-glucose turnover }} \times 100(\%)$

Glycogen synthase activity was measured essentially as described by Golden et al. [22]. Briefly, samples of muscle $(0.1 \mathrm{~g})$ or liver (0.1-0.2 g) were homogenised (Polytron Kinematica, Lucerne, Switzerland) in $1.0 \mathrm{ml}$ of Tris- $\mathrm{HCl}$ buffer, $\mathrm{pH} 7.8$, containing $10 \mathrm{mmol} / \mathrm{l}$ EDTA, $5 \mathrm{mmol} / 1$ dithiothreitol, $50 \mathrm{mmol} / 1 \mathrm{NaF}$, and $2.5 \mathrm{~g} / 1 \mathrm{rabbit}$ liver glycogen type III (Sigma, Poole, UK). The homogenate was centrifuged at $10,000 \mathrm{~g}$ for $30 \mathrm{~s}$ in an MSE microcentrifuge and the supernatant used for glycogen synthase assay by measuring the incorporation of UDP-U-14C glucose into glycogen at $30^{\circ} \mathrm{C}$. The final concentration of UDP glucose in the assay was $6.7 \mathrm{mmol} / \mathrm{l}$. Total glycogen synthase activity was measured in the presence of $10 \mathrm{mmol} / \mathrm{l}$ glucose-6-phosphate. One unit of enzyme activity is defined as the amount of enzyme catalysing the transfer of $1 \mu \mathrm{mol} / \mathrm{min}$ of glucose from UDP-glucose into glycogen at $30^{\circ} \mathrm{C}$.

\section{Other analyses}

Glycogen was determined by the amyloglucosidase method [23]. The intra-assay coefficient of variation (CV) was $6.1 \%$ at $8 \mu \mathrm{mol} / \mathrm{g}$ wet wt, when a muscle homogenate was assayed as multiple aliquots. 
Blood for estimation of intermediary metabolites was deproteinised with perchloric acid $(0.6 \mathrm{~mol} / \mathrm{l})$ and the extract assayed for lactate, pyruvate and alanine using automated enzymic fluorimetric methods [24]. Plasma insulin was determined by radioimmunoassay using a rat or human insulin standard (Novo Industri, Bagsvaerd, DK) as appropriate. Blood glucose was measured by a glucose oxidase method (Yellow Springs Glucose Analyser, Clandon Scientific, London, UK).

\section{Statistical analysis}

Results are presented as mean \pm SE. Significant differences between groups were assessed by Student's paired or unpaired t-test.

\section{Results}

\section{Blood glucose and serum insulin concentrations}

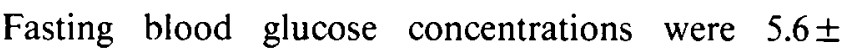
$0.1 \mathrm{mmol} / \mathrm{l}$ in the diabetic rats, compared to $3.6 \pm$ $0.1 \mathrm{mmol} / 1$ in the control rats $(p<0.001)$. During the euglycaemic clamp studies blood glucose was maintaind at $4.0 \pm 0.1 \mathrm{mmol} / \mathrm{l}$ in the diabetic rats and $4.0 \pm$ $0.1 \mathrm{mmol} / 1$ in the normal control rats. The coefficient of variation of blood glucose level calculated for each rat was $6.6 \pm 1.9 \%(\mathrm{SD})$ and $8.1 \pm 3.5 \%$ respectively.

Despite the higher blood glucose concentration, fasting insulin concentrations (rat assay) were similar in the diabetic rats $(0.78 \pm 0.13 \mu \mathrm{g} / \mathrm{l})$ and the normal control rats $(0.65 \pm 0.06 \mu \mathrm{g} / 1)$. Mean insulin concentration for the period 150 to $210 \mathrm{~min}$ was $128 \pm 7 \mathrm{mU} / \mathrm{l}$ (human assay) in the diabetic rats, and similar in the control rats $(124 \pm 6 \mathrm{mU} / 1)$.

\section{Glucose turnover and glucose carbon recycling}

In the fasting state 3-H-glucose turnover was significantly increased in the diabetic rats compared with normal control rats $(58 \pm 3$ versus $47 \pm 3 \mu \mathrm{mol}$. $\left.\min ^{-1} \cdot \mathrm{kg}^{-1}, p<0.05\right)$. Glucose metabolic clearance rate from plasma was not significantly different, however $\left(7.5 \pm 0.3\right.$ versus $\left.8.4 \pm 0.4 \mathrm{ml} \cdot \mathrm{min}^{-1} \cdot \mathrm{kg}^{-1}\right)$. In normal rats turnover had increased by 3.5 -fold by the last half hour of the clamp [Table 1] and was then significantly higher than in the diabetic rats (control rats, $161 \pm 17$, diabetic rats $107 \pm 4 \mu \mathrm{mol} \cdot \mathrm{min}^{-1} \cdot \mathrm{kg}^{-1}, p<$ $0.001)$.

Glucose infusion rate was also lower in the diabetic rats (86 \pm 9 versus $159 \pm 15 \mu \mathrm{mol} \cdot \mathrm{min}^{-1} \cdot \mathrm{kg}^{-1} \quad p<$ 0.001 ), so that calculated hepatic glucose output remained higher (diabetic rats, $21 \pm 4$, control rats, $2 \pm$ $\left.4 \mu \mathrm{mol} \cdot \mathrm{min}^{-1} \cdot \mathrm{kg}^{-1}, p<0.01\right)$.

Glucose carbon recycling was not statistically different in the diabetic rats compared to the control rats in the fasting state (Table $1,0.05<p<0.1$ ) or at the end of the clamp (Table 1). However while recycling was clearly similar in the control rats in the fasting and clamp states, it decreased from $19.3 \pm 1.8$ to $13.5 \pm$ $1.3 \%(p<0.05)$ in the diabetic rats.
Table 1. Glucose turnover and glucose carbon recycling in normal control rats and diabetic rats after a $24 \mathrm{~h}$ fast and during the last half hour of the clamp

\begin{tabular}{|c|c|c|c|c|}
\hline & $\begin{array}{l}\text { Plasma } \\
\text { glucose } \\
(\mathrm{mmol} / \mathrm{l})\end{array}$ & $\begin{array}{l}\text { 3-H-glucose } \\
\text { turnover } \\
\left(\mu \mathrm{mol} \cdot \min { }^{-1} \text {. }\right. \\
\mathrm{kg}{ }^{1}\end{array}$ & $\begin{array}{l}\text { 14-C-glucose } \\
\text { turnover } \\
\left(\mu \mathrm{mol}^{-} \cdot \mathrm{min}:\right. \\
\left.\mathrm{kg}{ }^{1}\right)\end{array}$ & $\begin{array}{l}\text { Glucose } \\
\text { carbon re- } \\
\text { cycling } \\
(\%)\end{array}$ \\
\hline \multicolumn{5}{|l|}{ Fasting } \\
\hline $\begin{array}{l}\text { Normal rats } \\
(n=14)\end{array}$ & $5.6 \pm 0.1$ & $47.2 \pm 2.5$ & $40.0 \pm 2.4$ & $15.2 \pm 1.1$ \\
\hline $\begin{array}{l}\text { Diabetic rats } \\
(n=14)\end{array}$ & $7.7 \pm 0.2^{\mathrm{a}}$ & $57.5 \pm 3.0^{b}$ & $46.4 \pm 2.7$ & $19.3 \pm 1.8$ \\
\hline \multicolumn{5}{|l|}{ Clamp } \\
\hline $\begin{array}{l}\text { Normal rats } \\
(n=7)\end{array}$ & $6.2 \pm 0.1$ & $161.1 \pm 17.0$ & $137.8 \pm 16.6$ & $14.5 \pm 1.4$ \\
\hline $\begin{array}{l}\text { Diabetic rats } \\
(n=7)\end{array}$ & $6.2 \pm 0.1$ & $107.1 \pm 4.0^{\circ}$ & $92.7 \pm 3.1^{\mathrm{c}}$ & $13.5 \pm 1.3^{\mathrm{d}}$ \\
\hline
\end{tabular}

Mean \pm SE. Half the animals were killed for tissue metabolic studies after the basal turnover investigations. ${ }^{a} p<0.05,{ }^{b} p<0.01,{ }^{c} p<0.001$ compared to appropriate normal control rats. ${ }^{\triangleleft} p<0.05$ compared to diabetic rats in the fasting state

Table 2. Liver and skeletal muscle glycogen concentrations in diabetic and normal rats in the fasting state and at the end of a hyperinsulinaemic glucose clamp

\begin{tabular}{lcc}
\hline Glycogen (umol/g wet wt) & Fasting & End of clamp \\
\hline Liver & & \\
$\quad$ Normal rats & $9 \pm 3$ & $38 \pm 6^{\mathrm{b}}$ \\
$\quad$ Diabetic rats & $11 \pm 4$ & $16 \pm 3^{\mathrm{c}}$ \\
Muscle & & \\
$\quad$ Normal rats & $16 \pm 1$ & $33 \pm 3^{\mathrm{b}}$ \\
Diabetic rats & $12 \pm 1$ & $22 \pm 2^{\mathrm{b}} \mathrm{c}$ \\
\hline
\end{tabular}

Mean \pm SE. $n=7$ for each group. a $p<0.01,{ }^{\mathrm{b}} p<0.001$ compared with fasted rats. ${ }^{c} p<0.05$ compared with normal control rats

\section{Liver and skeletal muscle glycogen-concentrations}

In the fasting state liver glycogen concentrations were low and did not differ between the two groups of rats (Table 2). At the end of the clamp there was a physiologically small but significant $(p<0.001)$ increment in liver glycogen concentration in the normal rats but not in the diabetic rats (Table 2). Diabetic rats had significantly lower liver glycogen concentrations at the end of the clamp compared with normal control rats $(16 \pm$ $3 \mu \mathrm{mol} / \mathrm{g}$ wet wt versus $38 \pm 6 \mu \mathrm{mol} / \mathrm{g}$ wet $\mathrm{wt}, p<$ $0.05)$.

Skeletal muscle glycogen concentrations in the fasting state were not different between the two groups of rats (Table 2). At the end of the clamp diabetic rats had significantly lower muscle glycogen concentration than normal control rats $(22 \pm 2 \mu \mathrm{mol} / \mathrm{g}$ wet wt versus $33 \pm$ $3 \mu \mathrm{mol} / \mathrm{g}$ wet $\mathrm{wt}, p<0.05$ ).

\section{Liver and skeletal muscle glycogen synthase activity}

In the fasting state both the glucose-6-phosphate independent form and total liver glycogen synthase activity were identical in the two groups of rats (Table 3 ). In the liver neither the active form of the enzyme nor total 
enzyme activity was influenced by the hyperinsulinaemic glucose clamp (Table 3 ).

Skeletal muscle glycogen synthase activity in fasting diabetic rats was not significantly different from that of control rats $(0.32 \pm 0.05 \mathrm{U} / \mathrm{g}$ wet wt versus $0.42 \pm 0.04 \mathrm{U} / \mathrm{g}$ wet $\mathrm{wt} ; 0.05<p<0.1)$. Total muscle glycogen synthase was also similar in the two groups of rats and did not change during the clamp studies (Table 3). In both groups of animals the active form of the enzyme was higher at the end of the glucose/insulin infusions than in the fasting state (control rats $60 \%$ increase, diabetic rats $44 \%$ increase). At the end of the clamp diabetic rats had a lower glucose-6-phosphate independent skeletal muscle glycogen synthase activity than control rats (Table 3, $p<0.01$ ). The percentage of enzyme in the active state at the end of the clamp was lower in the diabetic rats $(p<0.05$, Table 3$)$.

\section{Blood intermediary metabolite concentrations}

Blood intermediary metabolite concentrations in 24-h fasted rats at the end of the euglycaemic clamp are shown in Table 4. In the fasting state diabetic rats had significantly higher concentrations of blood glucose, lactate, pyruvate, alanine and glycerol (all $p<0.05$ ). Blood 3-hydroxybutyrate concentrations, however,

Table 3. Liver and skeletal muscle glycogen synthase activity beforc and after a $2.5 \mathrm{~h}$ hyperinsulinaemic glucose clamp in $24 \mathrm{~h}$ fasted diabetic and normal control rats

\begin{tabular}{|c|c|c|c|c|}
\hline & \multicolumn{2}{|l|}{ Normal rats } & \multicolumn{2}{|l|}{ Diabetic rats } \\
\hline & Fasting & End of clamp & Fasting & End of clamp \\
\hline \multicolumn{5}{|c|}{ Liver glycogen } \\
\hline Active & $0.20 \pm 0.02$ & $0.23 \pm 0.03$ & $0.19 \pm 0.02$ & $0.20 \pm 0.02$ \\
\hline Tota & $0.66 \pm 0.04$ & $0.69 \pm 0.05$ & $0.54 \pm 0.05$ & $0.55 \pm 0.06$ \\
\hline Percent active & $31 \pm 3$ & $33 \pm 2$ & $35 \pm 2$ & $35 \pm 3$ \\
\hline \multicolumn{5}{|c|}{$\begin{array}{l}\text { Muscle glycogen } \\
\text { Synthase (L/g wet wt) }\end{array}$} \\
\hline Active & $0.42 \pm 0.04$ & $0.67 \pm 0.05$ & $0.32 \pm 0.05$ & $0.46 \pm 0.04^{c}$ \\
\hline Total & $2.06 \pm 0.13$ & $2.04 \pm 0.14$ & $1.76=0.10$ & $1.83 \pm 0.11$ \\
\hline Percent active & $21 \pm 1$ & $33 \pm 2^{c}$ & $18 \pm 2$ & $25 \pm 2^{4,}$ \\
\hline
\end{tabular}

Mean \pm SE, $n=7$ in each group. As tissue studies involve animal killing, fasting and clamp studies are not paired. ${ }^{\mathrm{B}} p<0.05,{ }^{\mathrm{h}} p<0.01,{ }^{\mathrm{C}} p<0.001$ compared with the fasting state; ${ }^{d} p<0.05,{ }^{e} p<0.01$ compared with normal control rats at the end of the clamp were not different from those of control rats (Table 4). In normal rats, in response to the glucose clamp, blood concentrations of the glyconeogenic precursors lactate, alanine, and pyruvate increased whilst blood glycerol and 3-hydroxybutyrate concentrations decreased (Table 4). Although qualitatively similar changes were seen in the diabetic animals during the clamp, the changes were less marked. Thus, the concentrations of blood lactate and pyruvate were then decreased in the diabetic animals compared with controls $(p<0.001$ for both, Table 4), whilst blood glycerol and 3-hydroxybutyrate concentrations were significantly higher $(p<0.01$ for both, Table 4). In the normal rats the blood lactate and pyruvate concentrations at the end of the clamp correlated with glucose disposal $(r=0.84, p<0.01$, and $r=0.76, p<0.05)$.

\section{Discussion}

Insulin resistance is a well established feature of noninsulin-dependent diabetes in man, perhaps best characterised by glucose clamp studies combined with isotopic infusions, when both abnormalities of glucose production and utilisation can be described [25]. Insulin secretory abnormalities were recognised for many decades before resistance was characterised, and, perhaps because of the parallel with insulin-dependent diabetes, was generally assumed to be the primary cause of the condition. In recent years this assumption has been challenged with many workers suggesting that the primary abnormality may lie in the tissues responsible for glucose production and utilisation [11, 25]. In man it has proved impossible to separate insulin secretory disturbance from insulin resistance, as it is as yet not possible to provide physiological insulin replacement for a period of weeks, and all effective treatments for non-insulin-dependent diabetes appear to improve both secretion and insulin sensitivity [5-6].

Our approach in the current study is to ask whether the pathways of glucose production and disposal can be made resistant to insulin by the induction of specific islet B-cell damage. Islet transplant studies have made it possible to show that streptozotocin in a large

Table 4. Blood intermediary metabolite concentrations in $24 \mathrm{~h}$ fasted rats before and during a euglycaemic clamp

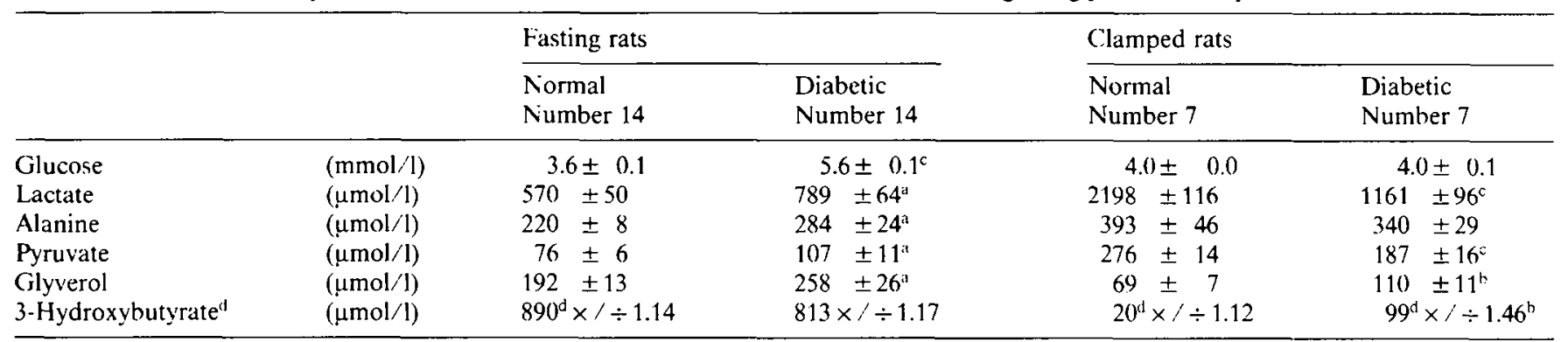

Results presented as mean \pm SE. ${ }^{a} p<0.05,{ }^{b} p<0.01,{ }^{c} p<0.001$ compared to normal control rats. ${ }^{d} 3$-hydroxybutyrate results were log transformed before statistical analysis to correct a skewed distribution, and standard crror is therefore prescnted as the tolerance factor 
dose $(150 \mathrm{mg} / \mathrm{kg})$ has no medium term metabolic effect on non-islet tissue $[16,17]$ many aspects of hepatic and peripheral metabolism being entirely normal.

Immunohistochemical studies confirm the site of action of the drug as being the islet B cell [26].

Streptozotocin is also used in the production of the conventional rat model of non-insulin-dependent diabetes, the neo-natal streptozotocin injection model [18]. As with our method that model depends on rejection of a proportion of streptozotocin-treated animals, and has the additional problem of maintaining an infection prone cohort of animals up to the time of study. The nature of the physiological disturbance has however been better documented for that model.

In the present study rats made diabetic with a much smaller dose of streptozotocin were selected for having a mild elevation of fasting blood glucose concentration, and were shown to have a $2-\mathrm{h}$ blood glucose concentration of only $12.0 \pm 0.6 \mathrm{mmol} / 1$ after a glucose load (Fig. 1). Even so they had a significant impairment of glucose disposal during a hyperinsulinaemic clamp performed at peak physiological postprandial insulin concentrations. In man clamp sensitivity is known to be largely determined by skeletal muscle glycogen storage [27], and it is therefore no surprise to find decreased end of clamp glycogen concentration and glycogen synthase activity in muscle from the diabetic animals. Assuming that a rat is $45 \%$ muscle by weight [28], and that the skeletal muscle sampled was typical in terms of glycogen storage, our figures suggest that about $30-35 \%$ of glucose infused appears as skeletal muscle glycogen, consistent with other reports for the rat [28]. This is much lower than estimates for euglycaemic clamp studies in man at peak postprandial insulin concentrations $[27,28]$, presumably reflecting the much higher ratio of glucose oxidation to storage in rats. This is supported by the much greater rise in blood lactate, pyruvate and alanine in these rat studies than seen in clamps in man. The unchanged percent recycling data would suggest that this rise in lactate, alanine and pyruvate is secondary to increased glycolytic flux rather than inhibition of hepatic uptake of these gluconeogenic precursors. It should be noted that the changes in lactate, pyruvate and alanine during the clamp parallel those of glucose turnover.

As glycolysis accounts for a large part of glucose disposal, the lower rise in lactate and pyruvate during the clamps, which parallels the reduced glucose turnover and muscle glycogen deposition, would appear to imply that the glycolytic pathway is affected by insulin resistance, as well as the pathway of glycogen storage.

It should be noted that we were unable to show a significant abnormality of glucose metabolic clearance rate under basal conditions in the diabetic animals. This suggests that glucose metabolism was not abnormal by non-insulin-dependent pathways, but this result should be interpreted cautiously in view of the small number of animals studied.
The clamp studies also demonstrate that hepatic glucose output is less effectively suppressed by insulin in the streptozotocin diabetic animals, with production rate remaining at $45 \%$ of normal fasting hepatic output, compared to $5 \%$ in the control animals. Again this hepatic insulin resistance is confirmed by liver glycogen concentrations at the end of the clamp. It will be noted that glycogen synthase activity was not different in the diabetic and control animals, but this enzyme is known to be unaffected by acute changes of insulin concentration in the rat liver [30]. Nevertheless, the diabetic animals, hyperglycaemic in the fasting state, show no activiation of glycogen synthase, contrary to the hyperglycaemic clamp studies [30]. This suggests that an elevation of portal vein insulin concentrations above fasting levels is a necessary setting for glucose stimulation of glycogen synthase or that the relative insulin deficiency or chronic hyperglycaemia of the diabetic animals causes a defect in liver glycogen synthase activation by glucose.

Our results extend the observations of Levy and others, who demonstrated abnormalities of glucose disposal using the glucose-insulin tolerance test in more severely diabetic rats showing growth retardation after neonatal injection of streptozotocin [14]. Kergoat and Portha, using the same neonatal streptozotocin model [13] failed to demonstrate insulin resistance using glucose clamps at very high insulin concentrations; but their study was complicated by anaesthesia and the need for different insulin infusion rates due to differences in plasma insulin clearance. In dogs insulin insensitivity after streptozotocin or alloxan has generally only been demonstrable with more marked disturbances of diabetes [30, 31], though Pupo and colleagues, [32] and Rossetti and colleagues using the pancreatectomised rat, [15], have reported insulin insensitivity even with only minor degrees of glucose intolerance.

If these results are applicable to man then they suggest that a specific islet B-cell defect could be responsible for the hepatic and peripheral insulin insensitivity found in non-insulin dependent diabetes, in accordance with the observations of insulin resistance in pancreatogenic diabetes [34], and of early insulin secretion abnormalities in familial Type 2 diabetes $[12,35]$.

Acknowledgements. This study was supported by the Wellcome Trust and the British Diabetic Association.

\section{References}

1. DeFronzo RA, Hendler R and Simonson D (1982) Insulin resistance is a prominent feature of insulin dependent diabetes. Diabetes 31: 795-801

2. Yki-Jarvinen H, Koivisto VA (1986) Natural course of insulin resistance in type 1 diabetes. $N$ Engl $J$ Med 315: 224-230

3. DeFronzo RA, Simonson D and Ferrannini E (1982) Hepatic and peripheral insulin resistance: a common feature of type II and type I diabetes mellitus. Diabetologia 23: 313-319 
4. Palmer JP, Benson JW, Walter RM and Ensinck JW (1976) Arginine stimulated acute phase of insulin and glucagon secretion in diabetic subjects. J Clin Invest 58: 565-570

5. Weir GC (1982) Non-insulin dependent diabetes mellitus. Interplay between B-cell inadequacy and insulin resistance. Am J Med 73: 461-464

6. Andrews WJ, Vasquez B, Nagulesparan M, Klimes I, Foley J, Unger R, Reaven GM (1984) Insulin therapy in obese, non-insulin dependent diabetes induces improvements in insulin action and secretion that are maintained for two weeks after insulin withdrawal. Diabetes 33: 634-642

7. Scarlett J, Gray R, Griffin J, Olefsky J, and Koterman O (1982) Insulin treatment reverses the insulin resistance of type II diabetes mellitus. Diabetes Care 5: 353--363

8. Olefsky JM and Reaven GM (1977) Insulin binding in diabetes: relationships with plasma insulin levels and insulin sensitivity. Diabetes 26: 680-688

9. Reaven GM, Miller RG (1979) An attempt to define the nature of chemical diabetes using a multidimensional analysis. Diabetologia $16: 17-24$

10. Ward WK, Johnston C, Beard JC, Benedetti TJ, Halter JB, Porte D (1985) Insulin resistance and impaired insulin secretion in subjects with a history of gestational diabetes mellitus. Diabetes $34: 861 \cdots 869$

11. Reaven GM (1984) Insulin secretion and insulin action in non-insulin-dependent diabetes mellitus. Which defect is primary? Diabetes Care 7 [Suppl 1]: 17-24

12. O'Rahilly SP, Nugent Z, Rudenski AS, Hosker JP, Burnett MA, Darling P, Turner RC (1986) Beta-cell dysfunction, rather than insulin insensitivity, is the primary defect in familial type 2 diabetes. Lancet II: $360-364$

13. Kergoat M, Portha B (1985) In vivo hepatic and peripheral insulin sensitivity in rats with non-insulin dependent diabetes in duced by streptozotocin: assessment with the glucose clamp technique. Diabetes 34: 1120. 1126

14. Levy J, Gavin JR III, Fausto A, Gingerich RL, Avioli LV (1984) Impaired insulin action in rats with non-insulin dependent diabetes. 33: 901-906

15. Rossetti L, Smith D, Shulman GI, Papachristov D, DeFronzo RA (1987) Correction of hyperglycaemia with phlorizin normalizes tissue sensitivity to insulin in diabetic rats. J Clin Invest 79: $1510-1515$

16. Kruszynska YT, Home PD, Alberti KGMM (1985) Comparison of portal and peripheral insulin delivery on carbohydrate metabolism in streptozotocin diabetic rats. Diabetologia 28: 167-171

17. Kruszynska YT, Home PD, Alberti KGMM (1985) Comparison of portal and peripheral insulin delivery on lipid metabolism in streptozotocin diabetic rats. Diabetes 34: 611-616

18. Bonner-Weir, Trent DF, Honey RN, Weir GC (1981) Responses of neonatal rat islets to streptozotocin: limited B-cell regeneration and hyperglycaemia. Diabetes 30:64-69

19. Kraegen EW, James DE, Bennett SP and Chisholm DJ (1983) In vivo insulin sensitivity in the rat determined by euglycaemic clamp. Am J Physiol 245: El-7

20. Somogyi MJ (1945) Determinations of blood sugar. J Biol Chem $160: 69-73$
21. Streja D) A, Steinger G, Marliss EB, Vranic M (1977) Turnover and recycling of glucose in man during prolonged fasting. Metabolism 26: 1089-1097

22. Golden S, Wals PA, Katz J (1977) An improved procedure for assay of glycogen synthase and phosphorylase in rat liver homogenates. Anal Biochem 77: 436-445

23. Keppler D, Decker K (1974) Glycogen determination with amyloglucosidase. In: Bergmeyer HU (ed) Methods of Fnzymatic Analysis. Academic press, New York, pp 1127-1131

24. Lloyd B, Burrin J, Smythe P, Alberti KGMM (1978) Enzymatic fluorometric continuous flow assays for blood glucose, lactate, pyruvate, alanine, glycerol and 3-hydroxybutyrate. Clin Chem 24: $1724-1729$

25. Kahn CR (1986) Insulin resistance: a common feature of diabetes mellitus. N Engl J Med 315: 252-254

26. Kruszynska YT, Home PD, Morley A, Alberti KGMM (1986) Preservation of islet function and morphology after transplantation into high dose streptozotocin diabetic rats. Diabetes Res 3: $175-181$

27. Kruszynska YT, Petranyi G, Home PD, Taylor R, Alberti KGMM (1986) Muscle enzyme activity and insulin sensitivity in type I (insulin dependent) diabetes mellitus. Diabctologia 29: $699-705$

28. Curtis-Prior PB, Trethewey J, Steward GW, Hanley T (1969) The contribution of different organs and tissues of the rat to assimilation of glucose. Diabetologia 5: 384-391

29. Katz LD, Glickman MG, Rapopart S, Ferrannini E, DeFronzo RA (1983) Splanchnic and peripheral disposal of oral glucose in man. Diabetes 32: 675-679

30. Kruszynska YT, Home PD, Alberti KGMM (1986) In vivo regulation of liver and skeletal muscle glycogen synthase activity by glucose and insulin. Diabetes 35: 662-667

31. Reaven GM, Szageman WS, Swenson RS (1977) Development of insulin resistance in normal dogs following alloxan-induced insulin deficiency. Diabetologia 13:459-462

32. Bevilacqua $S$, Barrett EJ, Smith D, Simonsen DC, Olsson $M$, Bratusch-Marrain P, Ferannini E, DeFronzo RA (1985) Hepatic and peripheral insulin resistance following streptozotocin-induced deficiency in the dog. Metabolism 34: 817-825

33. Pupo AA, Ursich MJM, Iamagvchi E, Vasconcellas FG (1976) Acute - and late - phase insulin secretion and glucose tolerance in mild alloxan diabetes in dogs. Diabetes 25: 161-166

34. Yki-Jarvinen H, Kiviluoto T, Taskinen M-R (1986) Insulin resistance is a prominent feature of patients with pancreatogenic diabetes. Metabolism 35: 718-727

35. Efendic S, Luft R, Wajnot $\wedge$ (1984) Aspects of the pathogenesis of type 2 diabetes. Endocr Rev 5: 395-425

Received: 29 September 1987

and in revised form: 7 March 1988

Dr. Y.T. Kruszynska

Department of Medicine

Royal Free Hospital

London NW3 2QG

UK 